\title{
Fairness and a Sustainable Society: Why Do We Care for the Education of Future Generations?
}

\author{
MiYADERA, Akio*
}

\begin{abstract}
Regarding education as 'the social' rather than an intentional action between individuals, this paper discusses the fair way of its distribution. Fairness is presumed to be relevant to the distribution of resources for education not only among people belonging to the same generation in the same society, but also among people belonging to different generations and different societies. To keep society sustainable and to leave a sustainable society to future generations, it is not sufficient to keep resources intact. It is also necessary to leave a fair way, i.e. the fair way of sharing burdens and benefits, for future generations. The educational significance of John Rawls' difference and just savings principles is elucidated in contrast to Robert Nozick's account of the entitlement of property. The main conclusion of the paper is that, if we see education as 'the social', we cannot design fair education without concern for the welfare of those who are living in different societies and are not yet born.
\end{abstract}

\section{Education as the social}

In this paper ${ }^{1}$ I will try to consider how relevant fairness is to education, particularly to the education of future generations, while assuming fairness to be relevant to the education of the present generation. Referring to this, I am going to view education as a social good that should be maintained at public cost just like the National Health Service is. At the same time, education shall be seen as a sort of social resource, which is neither produced limitlessly nor supplied plentifully because of the absolute restriction of funds and staff, and therefore subjects itself to the risk of scarcity. Such a specification of education as the social leads us to a consideration of fairness in sharing burden and benefit among us. If that is the case, is fairness also relevant to future generations in that we should allocate a proper amount of funds for their education? I suggest it is, since it would be unfair to make an estimate of the budget of education with no concern for future generations. This could potentially exert a negative influence upon their welfare.

Although it is impossible, both logically and actually, to know the inclinations of future generations in advance and meet their needs, we are responsible for determining the framework of their decisions concerning education. Will we push forward with an integrated society by retaining

\footnotetext{
* Tsukuba-Gakuin University

e-mail: miyadera@tsukuba-g.ac.jp
} 
education as a social good, or move backward toward a divided society by privatizing education according to preference? Which way we are going is simply left to our disposal, but it is probable that our collective choice will turn out to be a determinant to restrict the latitude of future decisions. They are vulnerable to our collective choice. That's the reason we have to be so fair-minded that we must respect the claim of every generation for equal treatment. Future generations ought to be qualified as those claimants who have a stake in our decisions regarding educational reform. Therefore we need an agent to represent their claims impartially, even though it would be extremely difficult to identify who he/she could be. Otherwise our free choice, which sounds like a private affair, must be done fairly in the public sphere where any participant will be welcome to explain his/her concerns. Fairness is always assured only in the policy of an open door for an outsider.

The content of the ensuing discussion is as follows:

In section 2, I ask why we have to preserve and, if possible, enrich resources available for future generations, and suggest that it would be inadequate to answer the question merely from humanitarian grounds. The question demands inquiry into the arguments about why we ought to act so fair-minded toward future generations. In section 3 , I refer to the difficulty peculiar to the educational relationship between generations apart from each other by contrasting it with the educational relationship between overlapping generations. Then, in section 4, I review the social and educational implications of John Rawls' just savings principle in which he argued for saving capital for future generations in terms of fairness. Rawls meant, by capital, both natural and cultural resources, including knowledge, learning and education. I will propose a feasible response to Rawls' original question: 'how far is the present generation bound to respect the claims of its successors' (Rawls 1971: 284). In section 5, I refer to the libertarian argument that stands in contrast to Rawls' principle of fairness and formulates forceful principles to legitimatize the ownership of property. Finally, in section 6, I emphasize that fairness is required not only to make our current society well-ordered, but to keep it sustainable so that it may hold enough resources for future people to make decisions at their discretion. Fairness is the basic principle according to which social goods are to be maintained and social resources are to be distributed within a generation and among generations as well. The main conclusion of the paper is that, if we see education as the social, we cannot design fair education without concern for the welfare of future generations.

\section{Intergenerational education}

As the studies of educational relationship have elucidated, whatever forms education may take, it is always performed in interaction between a grown-up generation and its growing counterpart: adults and children, masters and disciples. Intergenerational education is assumed to be indispensable not only for the full development of human potential, but for the steady conservation of social customs and political institutions as well. Caring for the next generation, i.e. raising our children and grandchildren, is needed to assure society of further prosperity to a degree of which flourishing lives in our later days are also contingent. Hence a practical motive for saving resources to be passed on to the next generation lies within our interests. However, there is no doubt that there is an altruistic motive to care for the next generation.

Harry Brighouse argued that all adults who became autonomous after having been educated in their schooldays should in turn fulfill the duty to maintain public education even if they have no children (Brighouse 2000: 13). He regarded it as an 'obligation' for adults to make commit- 
ments to the maintenance of public education. His remarks on 'obligation' are very familiar to the Japanese, because they tend to believe that the favor they received during childhood is a kind of indebtedness and ought to be repaid. Such indebtedness seems to correspond to a Japanese conventional virtue 'On'; 'On' is known widely in East Asian countries as one of the cardinal precepts of Confucianism.

Then, to whom should 'On' be repaid? Confucianism tells us to repay it to those to whom we owe it, especially to our own parents. 'On' that should be repaid to parents is also called 'Koh' in Japanese; 'Koh' corresponds to filial piety in English. Contrary to these Confucian precepts, Brighouse insisted properly that adults who grew up to be autonomous by having been educated in certain social circumstances should meet their obligation by contributing to the education of the next generation. I notice that Brighouse asked adults, but not just parents, to bear liabilities for maintaining common schooling for the next generation in the name of social justice, which, he argued, calls for fair education beyond difference of family backgrounds. I agree with Brighouse in saying that equality should prevail in compulsory education for all children living together in our society.

But, how can such an egalitarian principle be extended to apply to one generation after the next, and the next, and to the distant future generations, say, generations living in the late $22^{\text {nd }}$ century? Does our sense of fairness preclude that we should treat children of the distant future equally, just like our children are treated now? We are unlikely to have any practical motive to do so because our later lives, blessed or unblessed, will not be dependent on them. Nevertheless, if we were also to be fair to them, the practical reason would be that the natural and cultural resources, which have sustained our viability so far and made our lives worth living, are not necessarily the exclusive properties accessible only for the present generation, but the common properties available for every generation.

The premise of this reasoning, however, looks to be so idealistic that it could hardly endure criticism by every version of moral theory, from hedonism to stoicism. Actually we may be asked specifically how we could be so generous to future children while leaving quite a few children in our world deprived of basic goods, e.g. proper opportunities to attend primary schools. We might be asked further to state the reason why we should prefer equality among generations to equality among nations. Thus, we need more forceful arguments to justify fairness beyond generations. The point at issue is how and to what extent we can regard the obligation to future generations as justifiable without threatening the sustainability of our current society.

\section{Sustainability}

More than twenty years ago, the World Commission on Environment and Development (WCED, 1987), chaired by Gro Harlem Brundtland, provided us with a well-known definition of 'sustainability': 'Sustainable development is development that meets the needs of the present without compromising the ability of future generations to meet their own needs' (WCED 1987: 8). As is widely known, when the Brundtland Commission dealt with the problem of development in terms of sustainability, the Commission was looking to get past the trade-off between economic development and environmental protection. Accompanying this controversial topic, intergenerational relationship has been a crucial issue to be discussed in arriving at a clear meaning of 'sustainability'. But before discussing it, I think it is necessary, particularly for education, to make a 
distinction between two different sorts of intergenerational relationships: (a) the relationship of overlapping generations, and (b) the relationship of generations apart from each other in time, say, the relationship between us and persons living in the later part of the $22^{\text {nd }}$ century.

It is easy to understand what bearing the relationship of overlapping generations has on education; education is often defined as action by grown-up generations upon the growing. Without education in this sense no society can survive. Immanuel Kant is still famous for having explained the significance of intergenerational education as follows: 'Man can only become man by education. He is merely what education makes of him. It is noticeable that man is only educated by man - that is, by men who have themselves been educated' (Kant 1803 (Churton 1960): 6). A range of education that is carried out between overlapping generations has made it possible for man and society to make progress for eternal perfection throughout human history. Every generation has the inevitable mission to convey culture to the next generation without any break; culture is conveyed through the close relationship of overlapping generations.

On the other hand, the relationship of generations apart from each other appears to have no relevance to education because we don't have any chance to contact future generations nor the agency to act upon them. But, if we see education as the social rather than as the intentional action from person to person, then the study of educational relationship becomes long range as to cover the problems that emerged from intergeneration, namely, those problems never solved within a generation but handed over to succeeding generations. For instance, is it justifiable if we consume natural and cultural resources freely to deal with educational inequalities in our current society? Why do we have to bear the responsibility to balance those kinds of inequality that have been inherited from previous generations?

These problems imply that social and educational inequalities that emerged in our current society are too arduous and persistent for us to overcome, and that it is difficult to find decisive solutions within a generation. Excessive consumption of resources, even for the sake of the abolition of unjustifiable inequalities by applying equal distribution, is apt to threaten sustainability of our current society rather than to establish a just society at present. George Orwell's fable Animal Farm (1945) still affords a good lesson to us. Tackling the problem of social inequalities must not be entrusted entirely to the present leaders; commitment to it must be shared democratically among people and in part assigned to forthcoming generations. Thus, we need a thoughtful argument for fairness in distributing burden among generations.

\section{John Rawls and the just savings principle}

John Rawls' A Theory of Justice (1971) is well-known for its strong argument advocating equal liberty. His argument is grounded upon the principle of justice that, he insisted, is derived from the common sense of fairness. In this book Rawls made a sharp distinction between formal equality and fair equality of opportunities. In asking the government for a fair equality of opportunities, he sought 'to insure equal chances of education and culture for persons similarly endowed and motivated' (Rawls 1971: 275), rather than to place all persons on the same mark without regard to their given dispositions. He also applied an additional principle in order to compensate the least favored persons for their disadvantaged state: that is the difference principle. According to Rawls, the difference principle stipulates that defect in formal equality of opportunities based on natural liberty be replaced by democratic liberty that would be arrived at 'by combining the fair equality 
of opportunities with the difference principle' (Rawls 1971: 75).

The difference principle is, as Rawls suggested, the positive formulation of egalitarian principle to establish a just society, where '[s]ocial and economic inequalities are to be arranged so that they are both (a) to the greatest benefit of the least advantaged, and (b) attached to offices and positions open to all under fair equality of opportunities' (Rawls 1971: 83). Such a just society, as Rawls also conceded, will not be established within a generation. Yet, if we were to intend to abolish present inequalities utterly and establish a just society within our generation, we should set the social minimum 'at that point which maximizes the expectations of the least advantaged group' (Rawls 1971: 285), and cover the deficit by drawing the deposit which should be reserved as capital for future generations. If this state were to continue for some generations, it would finally result in an exhaustion of resources. Rawls sought to avoid it by applying another principle, the just savings principle, which demands that '[e]ach generation must not only preserve the gains of culture and civilization, and maintain intact those just institutions that have been established, but it must also put aside in each period of time a suitable amount of real capital accumulation' (Rawls 1971: 285). Rawls went on to say that saving capital would be necessary not merely for making investment in machinery but also in learning and education. Rawls saw education as a profitable enterprise in which to be invested for future generations. Education was expected as the capital that would provide future societies with promising developments and at the same time reduce our responsibility for the future to the extent that our current society could be sustainable. But, although investment in future education will bring benefit to both future generations and the present generation, does it entitle us to say that we treat future generations fairly?

When Rawls introduced the just savings principle in 1971, he seemed to do it on a presupposition that we cannot accept any longer in 2010: the presupposition that the descendent generations would be more blessed with resources, both natural and cultural, than any previous generation. This assumption is originally rooted in the progressive view of human history derived from the Enlightenment which has convinced us of an ever-growing society. We used to believe, at least until the end of the 1980's, in the idea of progress that future societies would be affluent in resources with ever-developing technologies. That's why Rawls did not necessarily wish to establish a just society in the present generation but entrusted it to future generations. But now we can't be so optimistic about an affluent future. Even though technology could make rapid progress, it would not always result in the well-being of all people in the future without the establishment of fair distribution of benefits produced by it. Indeed it is the fair distributive way of social goods, including education as the social, that we have to leave to future generations.

As Rawls asserted in the case of foreign aid, a liberal society has the duty to assist an illiberal society and even a society under tyranny so long as they intend to establish just institutions (Rawls 1999: 111). The aim of assistance is not to raise the average level of national wealth but to help social and political establishment of justice in those societies. Rawls saw a similarity between international aid and intergenerational savings. The savings principle is applicable to the present generation so long as it encourages future generations to take part in the establishment of a just society in the long run.

In addition, Rawls referred to an apparently juristic relationship between us and future generations, as if future generations would have a right to make claims against the present generation, such as: '[H]ow far [is] the present generation bound to respect the claims of its successors' (Rawls 1971: 284)? Whether future generations could enter into a social contract with us and have a justifiable right against us has been disputed in a lively manner among those who are concerned with 
Intergenerational Ethics. Instead of going into such an assumed situation, I mention the idea of 'a right that cannot be fulfilled' by which Derek Parfit discussed the difficulty to argue for the right of a child not yet born (Parfit 1984: 364). I suggest that the right of future generations is a sort of set of unfulfilled rights, and that the assumed claims of future generations based upon it would mislead us into thinking that we would be overburdened. It is not always necessary for our obligation to be grounded on the bilateral contract which distributes the right and the duty on both sides respectively; it is simply derived from the unilateral contract to help future generations to establish a just society. But, since the unilateral contract is easy to cancel or change because of the absence of an accuser, we need those regulatory principles that should keep us equitable in every generation. Among them it is the principle of fairness that asks us to treat every generation equally.

\section{Robert Nozick and the Lockean proviso}

Yet, a fundamental problem still remains unsolved: why we have to assist others by sharing our property, i.e. belongings obtained by our own efforts, with them, even though they have no common interest with us. Robert Nozick, whose work Anarchy, State, and Utopia (1968) is presumed to be representative of the libertarian argument, might insist that sharing property with others could infringe upon our ownership and that, if it were the case, it would be unjust in itself. While Nozick acknowledged and encouraged the voluntary transfer of goods from the well-off to the needy, he stood firmly against the compulsory redistribution of property possessed by fair means since it would possibly deprive a person of the entitlement to make use of his/her own property freely. Even the collective outcome by cooperative work, Nozick asserted, could and should be split up among those concerned fairly according to the extent of the contribution to the production (Nozick 1974: 186). Thus, Nozick's challenge was directed mainly against the distributive justice defended by John Rawls, falling back on John Locke's standard argument for property that was invented to legitimatize private ownership by stating the labor theory of value: 'The labour of his body, and the work of his hands, we may say, are properly his. Whatsoever then he removes out of the state that nature hath provided, and left it in, he hath mixed his labour with, and joined to it something that is his own, and thereby makes it his property' (Locke 1690 (Laslett 1967): Sec. 26). Following such reasoning that intended to encourage the development of natural resources, Nozick formulated two principles of justice to legitimatize it, e.g. the justice of acquisition and the justice of transfer (Nozick 1974: 150), instead of reassessing the rectificatory justice that would demand public compensation for burdened persons. It is assumed that a person is entitled to hold any property exclusively so far as he/she gained it through just means of acquisition and transfer.

Together with body and hand, Nozick also ascribed the natural talent, both physical and mental, and its products to the property of the person, and rejected the conception of faculties as a common asset. How much talent is endowed each person may be arbitrarily designed by nature, but differences in the extent of talent among people are justified by way of its acquisition. That someone is endowed with great talent is just, since it never causes the reduction of the natural talent of anyone else. How to use such gifted talent is utterly up to the discretion of the possessor; no one can compel him/her to utilize it on behalf of others. Nozick's defense, in terms of the just acquisition, of the different assignment of natural talents among people stands in sharp contrast to Rawls' account of the unjust distribution of natural talents in society. Rawls called for reciprocal 
assistance to rectify inequality, while Nozick did not see it as necessary to assist others by transferring goods at the risk of harming their autonomous living.

Nozick's argument for the entitlement of property has social significance in establishing the proprietary relationship of those who belong to the same generation in the same society. Then, is it also applicable to the relationship between those who belong to different generations? In other words, do we have a claim for entitlement against future generations? If we have this, we don't need to be concerned about saving anything, at least our own products, for use by future generations. On the contrary, if future generations are blessed with the same entitlement as we have now against each other, we have obligations to save resources for them so as to develop their own possibilities. To consider these issues, it will be helpful to refer to the reservation with which Locke legitimatized his argument for property.

John Locke began his argument for property with the major premise that God 'hath given the world to men in common', and asked 'how men might come to have a property in several parts of that which God gave to mankind in common' (Locke 1690 (Laslett 1967): Sec. 25, 26. Italics added). According to Locke it is not to persons belonging to a particular generation, say, current generation, but to mankind enduring beyond generations that God gave the world. Moreover, God did not merely give the world to mankind in common, but also provided mankind with the 'reason to make use of the world to the best advantage of life' (Locke 1690 (Laslett 1967): Sec. 26). So everyone has a right to hold possession of what he/she yielded by mixing his/her own labor to the world, but his /her claim will be authorized 'at least where there is enough, and as good, left in common for others' (Locke 1690 (Laslett 1967): Sec. 26). This reservation is known as the Lockean proviso.

The Lockean proviso asks one not to exhaust the world God gave to mankind in common, but to set aside enough resources for others, including people of the future generations, to set up their own ways of living in a condition equal to ours. Thus the ownership of private property should be legitimatized not only by the just ways of acquisition and transfer, but also by the mutual respect of each other, e.g. the principle of fairness.

\section{The principle of fairness}

As the rule of fair play suggests, the principle of fairness is the principle that asks one to apply to oneself the same rules that one applies to others. In other words it implies mutual obligation to put oneself in the other's shoes and encourages one to think about one's position from the other's side. Therefore, mutuality or reciprocity is one of the main points of the principle of fairness.

Then, who is the other? Speaking generally he/she may be a stranger or a rival as well as a neighbor or a friend. Even an opponent can be as useful as the other so long as his/her reason against us is comprehensible. In fact we need opposing arguments by the other to make our own way seem more appropriate. How, then, about future generations? It may be controversial to place them on the same level as strangers living in our world, since we can not comprehend by any means what claims they may have against us. But we can attempt to put ourselves in the place of future generations and think about our position from their side. Moreover, including them as the other will urge us to reconsider if our way is fair to everyone in our world. As stated above, future generations would have neither the justifiable right to make claims against us nor the mutual obli- 
gation to do something for us, and yet they could be regarded as the regulatory principle according to which we should decide the way to distribute social goods fairly among us.

I suggested the necessity for the principle of fairness in the main title of this paper: Fairness and a Sustainable Society. To keep society sustainable and to leave a sustainable society to future generations, it is not sufficient to keep resources intact. It is also necessary to leave a fair way, i.e. the fair way of sharing burdens and benefits, for future generations. For the present, we have to find a way to distribute education as the social, fairly to children belonging to different nations in our world. What nations they belong to, and which generations they are born in, are both arbitrary if we apply the principle of fairness seriously.

\section{Note}

1 This article is the enlarged version of the keynote address at the International Conference on Philosophy of Education, held at Korea University, Seoul, June 12, 2010. The common subject at the Conference was 'Education for the Sustainable Future'.

\section{References}

Brighouse, H. (2000). School Choice and Social Justice, Oxford University Press.

Kant, I. (1803). Education, translated by Churton, A. (1960), The University of Michigan Press.

Locke, J. (1690). Second Treatise of Civil Government, edited by Laslett, P. (1967), 2nd ed., Cambridge University Press. Nozick, R. (1974). Anarchy, State, and Utopia, Basil Blackwell.

Parfit, D. (1984). Reasons and Persons, Clarendon Press.

Rawls, J. (1971). A Theory of Justice, Oxford University Press.

Rawls, J. (1999). The Law of Peoples, with "The Idea of Public Reason Revised", Harvard University Press.

WCED (World Commission on Environment and Development) (1987). Our Common World, Oxford University Press.

\section{Acknowledgement}

For comments on earlier drafts, I am grateful to Prof. Robert Juppe, Tsukuba-Gakuin University. This work was supported by Grant-in-Aid for Scientific Research (B) of KAKENHI (2233036 Project leader: HIROTA, Teruyuki). 